\title{
ANALYSIS OF ONLINE MEDICAL SERVICES AVAILABILITY DURING COVID-19 PANDEMIC IN NEPAL
}

\author{
Ramesh Kumar Maharjan ${ }^{1^{*}}$, Shirshak Koirala ${ }^{2}$, Rashmisha \\ Maharjan $^{3}$, Jeevan B. Sherchand ${ }^{4}$
}

${ }^{1}$ Dr. Maharjan is an Associate Professor, Department of GP \& Emergency Medicine, $M M C$, Institute of Medicine, Tribhuvan University, Kathmandu, Nepal

${ }^{2}$ Dr. Koirala is a Medical Officer, Trainer, Nepal Disaster and Emergency Medicine Center, Lalitpur, Nepal

${ }^{3}$ Dr. Maharjan is a Coordinator, Nepal Disaster and Emergency Medicine Center, Lalitpur, Nepal

${ }^{4} \mathrm{Dr}$. Sherchand is Coordinator of Knowledge Management and Health Policy, Nepal Health Research Council, Nepal

*Corresponding Author: ramesh.maharjan@mmc.tu.edu.np

\begin{abstract}
After the first case of COVID-19 reported from Wuhan City in China, the WHO declared it as a 'pandemic' on $11^{\text {th }}$ March 2020. The first case of COVID-19 was officially announced in Nepal on $24^{\text {th }}$ January 2020. The lockdown of the entire nation was implemented by the government of Nepal from $24^{\text {th }}$ March 2020 following the announcement of the second positive case of COVID-19. The aims of the study to find out the available online services understand and analyze them to implement in Nepal.

There are 10 online medical services operating to facilitate medical services and 13 Covid-19 related mobile apps to use by common public and medical surveillance within Nepal. These are online mobile application and online services dedicated to make life easy during Covid - 19 Pandemic in Nepal. It is better to apply single or minimize duplication of similar work for Covid-19 Pandemic in Nepal by different concerned authorities.
\end{abstract}

Keywords: COVID-19 - lockdown - online medical service - Nepal 


\section{INTRODUCTION}

After the first case of COVID-19 reported from Wuhan City in Hubei province, China on $31^{\text {st }}$ December 2019, the WHO declared COVID-19 as an outbreak of 'Public Health Emergency of International Concern' on $30^{\text {th }}$ January 2020 and 'pandemic' on $11^{\text {th }}$ March 2020. The first case of COVID-19 was officially announced in Nepal on $24^{\text {th }}$ January 2020 . The lockdown of the entire nation was implemented by the government of Nepal from $24^{\text {th }}$ March 2020 following the announcement of the second positive case of COVID-19. To serve the population during the time of pandemic, there were different online medical services in operation providing variety of services in Nepal. In this article, we describe our findings related to available online medical services for COVID-19 pandemic in Nepal.

In Nepal also, online consultations offer potential advantages to patients (who are spared the cost and inconvenience of travel) and healthcare system but fears have been expressed that they may be clinically risky and/ or less acceptable to patients or staff, and they bring significant technical, logistical and regulatory challenges (Greenhalgh et al. 2016). The Internet has been a steady source of medical data that has late been utilized for online private patient-doctor consultations, also need public. The published work/ reports/surveys, the various factors which led to a sudden surge in the online medical consultation are the convenience, shift in disease patterns, costeffective, privacy and second opinion (Singh et al. 2018). The Tele-Doc's potential for addressing more complex problems and achieving efficiency is less clear, and its adoption may involve unforeseeable consequences (Casey et al. 2017).

The findings offer managerial insights on managing patients' continuous consultation behaviors and enhancing their satisfaction by considering time scope and service type with important insights into how online medical care can be delivered more effectively, so relieving the demand for traditional healthcare system capacity (Yang et al. 2019). the promoting multiple timely responses in patient-provider interactions is essential to encourage payment (Jiang et al. 2020). Policies and promotions could attract more doctors to provide Web-based consultation and result 
could be a reference for policy making to improve the medical system both online and offline (Lil et al. 2019).

The healthcare industry changes all the time to accommodate new research findings and integrate new treatments in Private sector. Yet today's medical industry is changing like never before in new and major ways, all are due to growth of the Internet and prevalence of devices like smartphones and tablets. Healthcare is now at the beginning of a massive shift in how providers deliver patient care, and telehealth companies that provide online access to physicians and medical team are flourishing.

In addition, there are already running various online medical services for the benefit of patients. Hence, these are some example on it as a "study has revealed that history taking skill and practice is dearth mainly in lower level physicians (medical officers/Interns and junior faculties). Thus, hospital authorities should give attention to improve communication skills of physicians and all level of medical team" (Paudel et al. 2017).

Also, it is seen in running online hospital services for "Patient satisfaction is one of the most desired outcomes of health care and it is directly related with effective utilization of healthcare service which make service more responsive to the patient, the hospital management needs to improve the staff behavior, adequate supply of lab tests and drugs and focus on reducing the waiting time" (Rajbanshi et al. 2014).

The general objective of the current study was to analyze available online medical services during Covid-19 Pandemic in Nepal. Whereas, specific objectives were (i) to find out number of available online medical services, (ii) to analyze status of the available services and (iii) to determine basic comparative analysis of available services.

\section{METHODOLOGY}

We used internet resources to find out about various available online medical services. We included all the medical services which were online and could be benefitted by the consumer, staying at their home.

We excluded all the services which were not related to Nepal and those which were not entirely online and needed service provider or 
receiver to get out of the house and required physical interaction. The online service providers available from January, 12020 to May 30, 2020 has been included and analysed.

Process: Online Research by using Google Drive with key words "Nepal, online medical service, Covid-19 Pandemic.

Criteria: Online Medical Services, Apps, Surveillance System for Covid-19 Pandemic situation in Nepal by Government and Non-Government Organizations of Nepal.

Numbers: 10 online medical services and 13 online medical apps are analysed.

It is prospective, descriptive cross sectional qualitative study. Data are analysed by use of Google Drive and available websites.

\section{RESULTS}

Medical Online Services available during COVID-19 Pandemic in Nepal as depicted in Table 1 and 2. The findings showed that there are mainly two varieties of services available as mentioned in the 'Service' section in the tables. One of them, to provide medical consultation to the patients via online media such as web and app based software, referred to as 'Online Consultation' while the other are specifically related to COVID-19 pandemic assessment tool.

The first three services mentioned in the above table were specifically related to COVID-19 pandemic assessment. Among them, Nepal COVID-19 Surveillance System and Self-Assessment app can perform added service - surveillance along with verification and geo location tracking services as well, while other two do not possess the facility to surveillance and verification. 


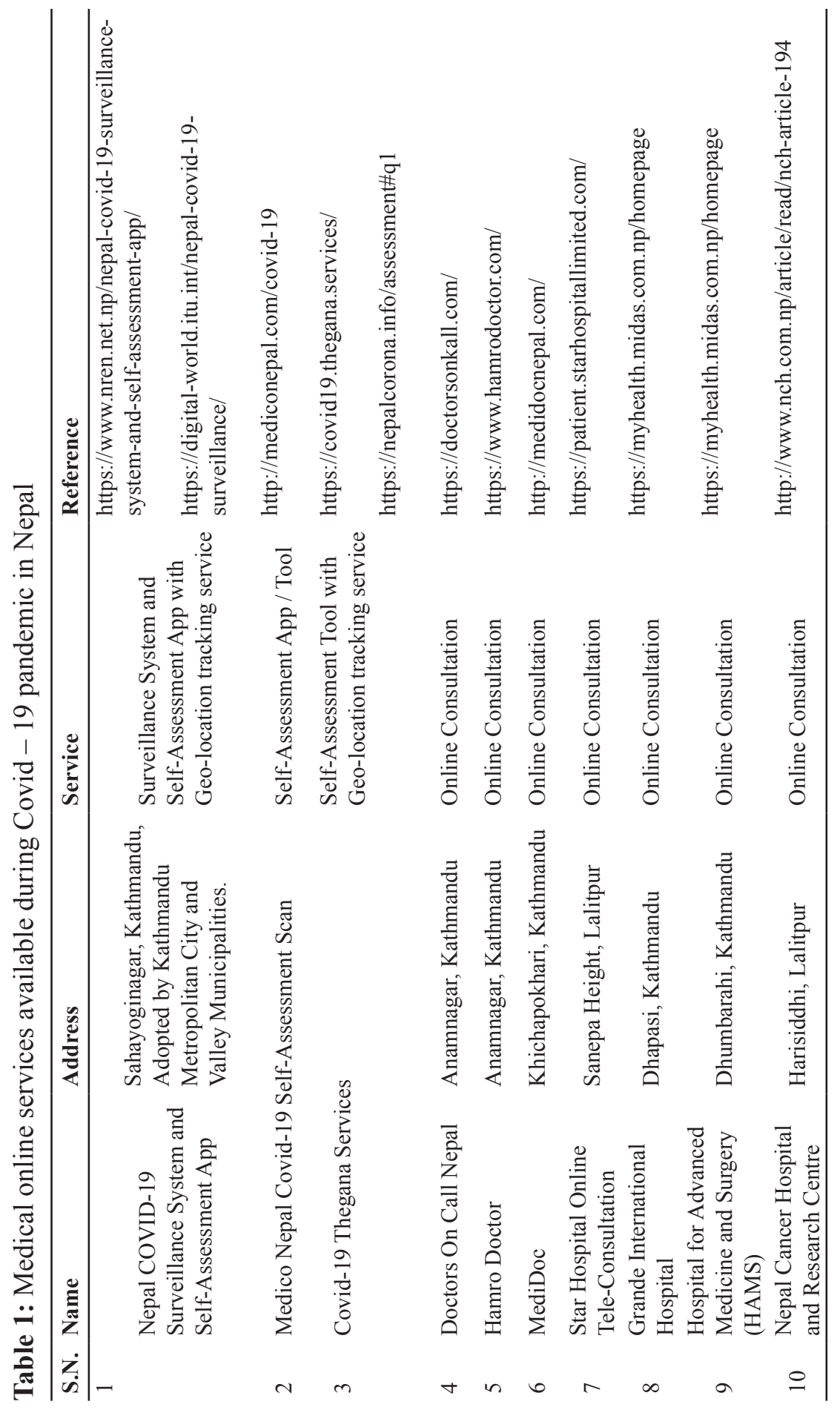




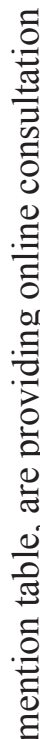

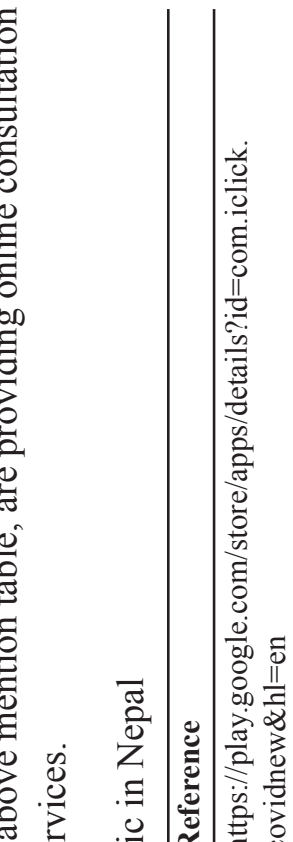

䓠
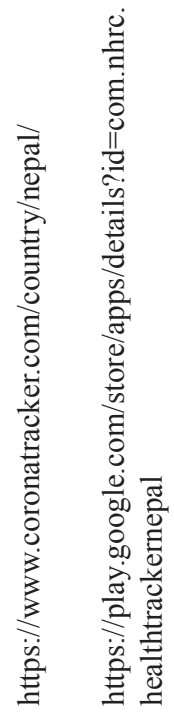

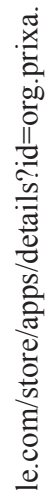

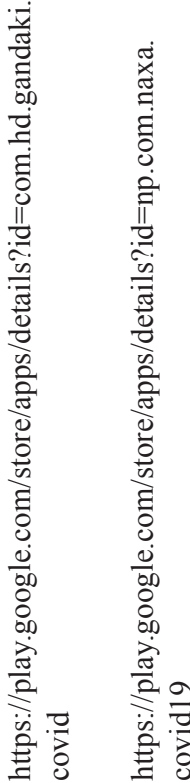

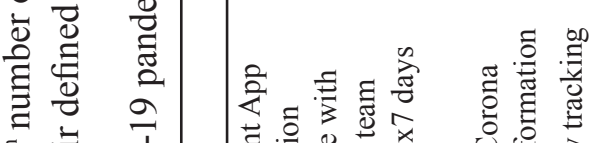

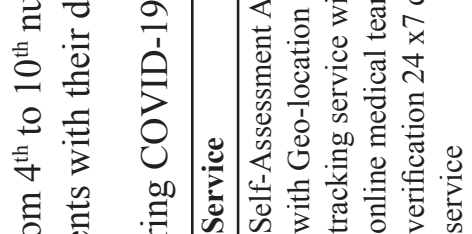

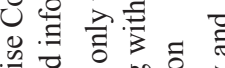

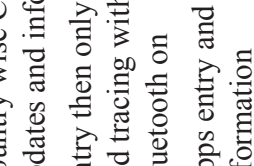

$\operatorname{lic}_{0.0}$

窟泀

空递

\section{을}

寻

i

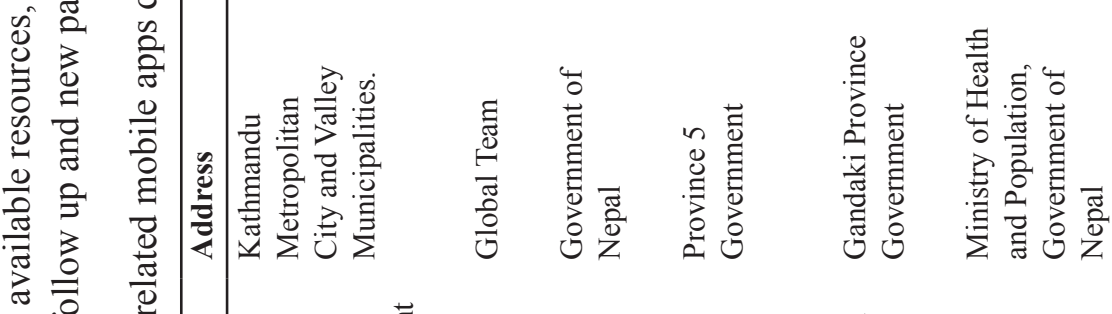

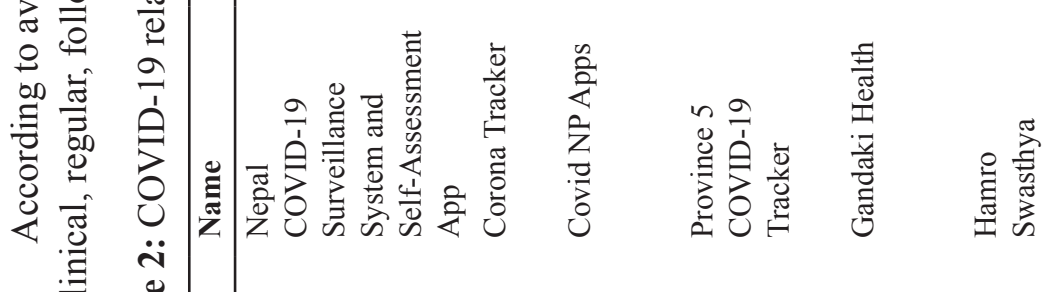

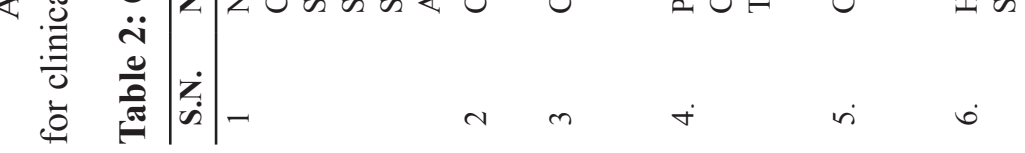



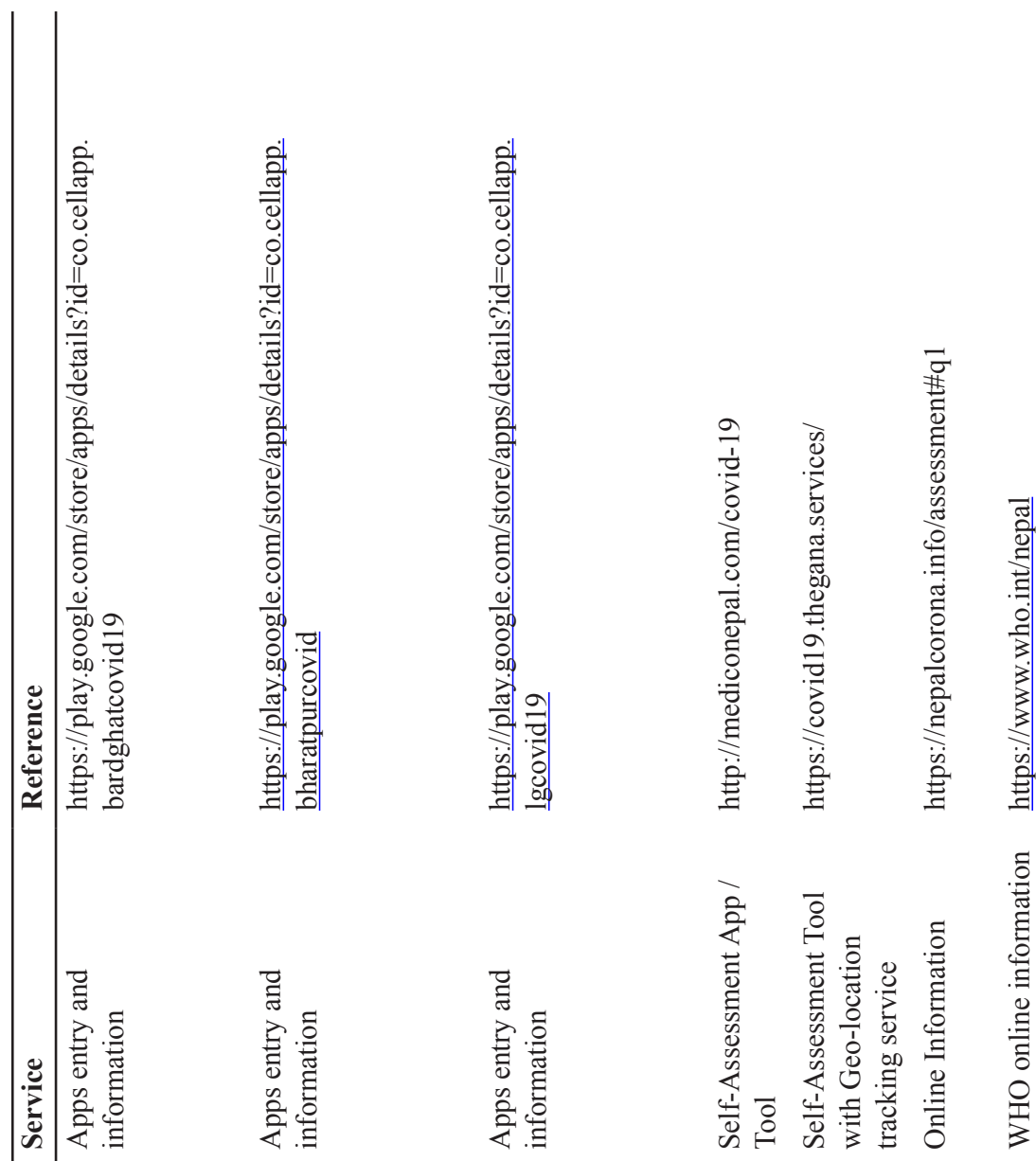

를

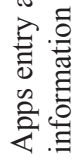

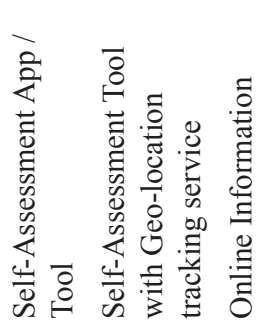

:

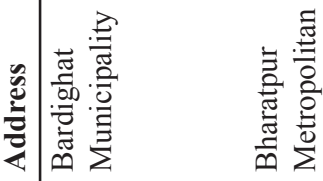

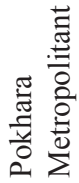

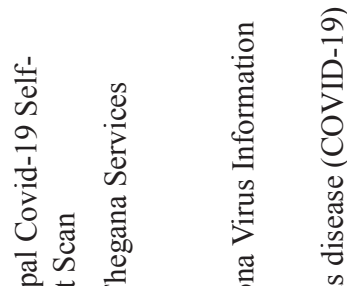

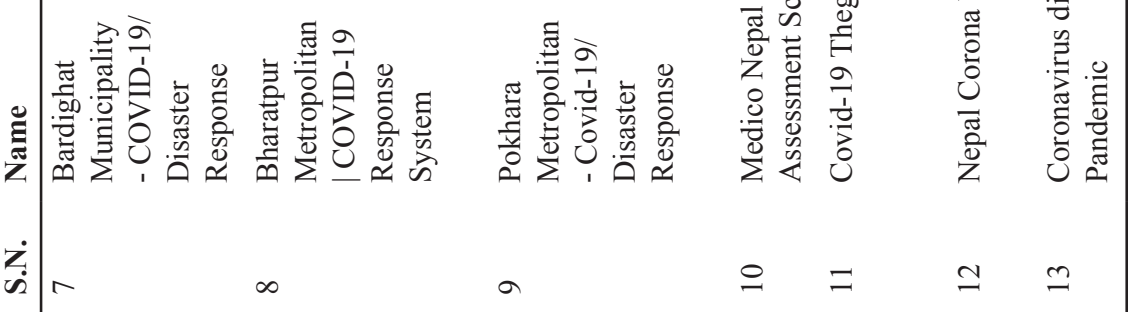


According to search online with Covid 19 Apps using in Nepal, there were 13 Mobile apps available till 30th May 2020. These were made under Government of Nepal and its Different level government to local level of government. There was separate Mobile Apps by Central Government of Nepal named Covid NP, whereas Hamro Swasthya Mobile Apps by Ministry of Health and Population. There were different Mobile apps according to name by respective Province Government as by Province 5 and Gandaki Province. There were other different Mobile Apps developed under Municipalities and Metropolitan Cities, namely by Kathmandu Metropolitan City, following by Bharatpur and Pokhara Metropolitan Cities. There were other different organization own mobile apps including World Health Organization.

\section{DISCUSSION}

With COVID-19 Pandemic in Nepal, it looks another influx of Mobile Apps for using during Covid-19 Pandemic in Nepal. Despite of those available Mobile apps, general people need to aware to choose the correct apps for them according to their location. However, it is not an easy task to choose and apply to link in main stream of this pandemic in Nepal. Government of Nepal has its own, lately introduced the Covid NP in early week of May 2020 whereas Nepal Covid 19 Surveillance System (NC19SS) under Kathmandu Metropolitan City had been lunch it on March 2020 and applied in the entire Kathmandu Valley. Following by NC19SS, Hamro Swashya Mobile Apps has been using by Ministry of Health and Population, Government of Nepal. Rests of other apps are following those apps in their respective province and local government.

Moreover, among 10 online Medical Services, only NC19SS is only the Mobile Apps and Medical On duty Team online service application as well as it is also the only one application among other 13 mobile apps using for Covid 19 Pandemic period in Nepal. Most of the apps claim that these are using for tracking and tracing the cases, NC19SS has full features of GIS system with mapping and further action. Covid NP needs to use Bluetooth for tracking and tracing, not well known its application online information. There are also another application using by Nepal Army for Tracking and Tracing but it is not available online publically. Hamro Swasthya Apps is also using by MoHP for cases entry by direct calling following by tracking and tracing the cases all over the Nepal. Others apps are more informative of Covid 19 and updates national and international cases. 
There are different modalities in the World as well but not much of such application for single disease by different government organization as in Nepal. Therefore, Government must look its importance and applicability without duplicability in making, application of such apps for public. It is also necessary to make a standard format and national online medical service for uniformity of healthcare service without discrimination of Private and Public Hospitals and Institutions. There is also lack of national data gathering of multiple apps resources due to many diversity of apps for Covid-19 in Nepal.

\section{CONCLUSION}

The above illustrated findings and results showed that we have been able to initiate alternative measures to provide services, surveillance and assessment tools via online means during this COVID-19 pandemic lockdown period in Nepal. However, the services are limited within the perimeter of Kathmandu Valley and Major Cities and has not been able to cover the population of the entire nation due to lack of common people access to internet and mobile phone.

Since, the data indicated that, above are entirely based on Google search network findings; the study itself is not adequate to draw a conclusion to current status of online medical services and benefit of apps within Nepal. However, we can trace and tracking by mobile phone that made easy an outline to the online medical service scenarios and challenges in Nepal. There are possibilities for further exploration and analysis of online medical services in Nepal and their development for preparation and effective role in future unseen pandemics and disasters.

\section{DECLARATION:}

We have no conflict of interest.

\section{REFERENCES}

Casey, M., Shaw, S. \& Swinglehurst, D. (2017). Experiences with online consultation systems in primary care: case study of one early adopter site; e736. British Journal of General Practice.

Greenhalgh, T., Vijayaraghavan, S., Wherton, J., Shaw, S., Byrne, E., Campbell-Richards, D., et al. (2016). British Medical Journal Open: first published as 10.1136/BMJ open-2015-009388 
Jiang, J., Cameron, A. F. \& Yang, M., (2020). Analysis of massive online medical consultation service data to understand physicians' economic return: Observational data mining study. Journal of Medical Internet Research Medical Information, 8(2): e16765, doi: $10.2196 / 16765$

Li1, Y., Xiangbin, Y. \& Song, X. (2019). Provision of Paid Web-Based Medical Consultation in China: Cross-Sectional Analysis of Data from a Medical Consultation Website. Journal of Medical Internet Research, 21(6): 12126. doi: 10.2196/12126.

Paudel, S., G.C., K.B., Subedi, M., Arjyal, A., Dahal, S.K., Lamichhane, B., et al. (2017). Communication skills of physicians during consultation in out-patient settings at a tertiary hospital in Nepal. World family medicine/Middle East Journal of Family Medicine, 15(10):17-24.

Rajbanshi, L., Dungana, G.P., Gurung, Y.K. \& Koirala, D. (2014). Satisfaction with health care services of outpatient department at Chitwan Medical College Teaching Hospital, Nepal. Journal of Chitwan Medical College, 4(7): 11-18.

Singh, A.P., Joshi, H.S., Singh, A., Agarwal, M. \& Kaur, P. (2018). Online medical consultation: A review. International Journal of Community Medicine and Public Health, 5(4):1230-1236

Yang, Y., Zhang, X. F. \& Lee, P. K. C., (2019). Improving the effectiveness of online healthcare platforms: An empirical study with multiperiod patient-doctor consultation data. International Journal of Production Economics, 207: 70-80 